\title{
Refractory Hodgkin Lymphoma
}

National Cancer Institute

\section{Source}

National Cancer Institute. Refractory Hodgkin Lymphoma. NCI Thesaurus. Code C8836.

Hodgkin lymphoma resistant to treatment 